\title{
A Novel Cellular Model to Study Angiotensin II AT2 Receptor Function in Breast Cancer Cells
}

\author{
Sylvie Rodrigues-Ferreira, ${ }^{1,2,3}$ Marina Morel, ${ }^{1,2,3}$ Rosana I. Reis, ${ }^{4}$ Françoise Cormier, ${ }^{1,2,3}$ \\ Véronique Baud, ${ }^{1,2,3}$ Claudio M. Costa-Neto, ${ }^{4}$ and Clara Nahmias ${ }^{1,2,3}$ \\ ${ }^{1}$ Inserm, U1016, Institut Cochin, Paris, France \\ ${ }^{2}$ CNRS, UMR 8104, Paris, France \\ ${ }^{3}$ University Paris Descartes, Paris, France \\ ${ }^{4}$ Department of Biochemistry and Immunology, Faculty of Medicine at Ribeirao Preto, University of São Paulo, \\ 14049-900 Ribeirao Preto, SP, Brazil
}

Correspondence should be addressed to Sylvie Rodrigues-Ferreira, sylvie.rodrigues-ferreira@inserm.fr

Received 29 June 2011; Revised 6 September 2011; Accepted 6 September 2011

Academic Editor: Jean-Marie Zajac

Copyright (C) 2012 Sylvie Rodrigues-Ferreira et al. This is an open access article distributed under the Creative Commons Attribution License, which permits unrestricted use, distribution, and reproduction in any medium, provided the original work is properly cited.

\begin{abstract}
Recent studies have highlighted the AT1 receptor as a potential therapeutic target in breast cancer, while the role of the AT2 subtype in this disease has remained largely neglected. The present study describes the generation and characterization of a new cellular model of human invasive breast cancer cells (D3H2LN-AT2) stably expressing high levels of Flag-tagged human AT2 receptor (Flag-hAT2). These cells exhibit high-affinity binding sites for AngII, and total binding can be displaced by the AT2-selective antagonist PD123319 but not by the AT1-selective antagonist losartan. Of interest, high levels of expression of luciferase and green fluorescent protein make these cells suitable for bioluminescence and fluorescence studies in vitro and in vivo. We provide here a novel tool to investigate the AT2 receptor functions in breast cancer cells, independently of AT1 receptor activation.
\end{abstract}

\section{Introduction}

Angiotensin II (AngII) is the biologically active peptide of the renin-angiotensin system, a well-known regulator of cardiovascular homeostasis and brain functions [1,2]. Over the past ten years, a large number of studies have unraveled an additional role for the renin-angiotensin system in proliferative pathologies such as hyperplasia and cancer [3-8]. AngII binds to two major subtypes of receptors, namely, AT1 and AT2. It is generally admitted that AT1 receptor activation is responsible for most of the reported effects of AngII, whereas the AT2 receptor behaves as a negative regulator of AT1 signaling pathways [9-11]. Indeed, functional negative crosstalk between AT1 and AT2 receptors has been largely described in several physiopathological conditions including hypertension $[1,10,11]$. Activation of the AT1 receptor triggers a large number of intracellular kinases leading to modulation of cell proliferation, migration, and inflammation, three processes closely associated with tumor progression. Accordingly, several groups have shown that blocking AT1 receptors using specific receptor antagonists (ARBs) is effective in reducing tumor growth and metastasis in preclinical models [12-16]. Studies using knockout animals have further pointed out a role for stromal AT1 receptors from the host in tumor-associated macrophages infiltration and in cancer-related angiogenesis $[17,18]$.

A recent study [19] showing a dramatic overexpression of AT1 receptors in a subpopulation of invasive breast tumors has highlighted the potential use of ARBs as novel therapeutic agents against breast cancer. Indeed, it has been shown that losartan, an AT1 receptor blocker, was able to inhibit breast tumor growth and invasion, suggesting that effective treatments for breast cancer may be developed using drugs already used in clinics with few side effects. These exciting findings have, however, been challenged by a recent meta-analysis that suggested that ARBs medication may be associated with increased risk of cancer [20]. These 
provocative results have not been further validated by other groups, which rather found no effect of ARBs related to the risk of cancer $[21,22]$. Nevertheless, the beneficial effects of angiotensin receptors blockade in cancer still remain a matter of debate and need to be better explored, possibly with the use of new models.

To date, most studies have mainly focused on the role of the AT1 receptor in cancer, while the role of the AT2 subtype has been largely neglected. Discrepancies in metaanalysis studies might reflect variable levels of expression of AT2 receptors in different tumors. It is important to keep in mind that antagonizing the AT1 receptor by ARBs leaves the AT2 receptor fully available for activation by local AngII. Thus, it is essential to determine whether the AT2 receptor antagonizes, or mimics, the effects of the AT1 subtype on cancer cell proliferation and invasion.

Recent studies examining the effects of AT2 receptors in cancer have remained controversial. Expression of AT2 receptors from either the tumor or stroma has been shown to attenuate the growth of pancreatic carcinoma [23], lung adenocarcinoma [24], and pheochromocytoma [25]. In contrast, other studies indicate that AT2 receptor expression associates with poor prognosis of astrocytomas [26] and that its deletion or blockade delays tumor vascularization and progression [27]. Still little is known about the effects of AT2 receptors in breast cancer. Expression of AT2 receptors in luminal epithelial cells of the normal breast has been shown to be significantly increased in breast hyperplasia and carcinomas [28]. AT2 may thus represent a new therapeutic target against breast cancer, and elucidating the functional role of these receptors in breast cancer is of major importance.

The aim of the present study was to provide a cellular model for proper investigation of the effects of the AT2 receptors in breast cancer progression.

\section{Materials and Methods}

2.1. Breast Cancer Cell Line. The D3H2LN cancer cell line (obtained from Caliper's) is a luciferase-expressing cell line that was derived from a spontaneous lymph node metastasis of MDA-MB-231 human breast adenocarcinoma cells [29]. D3H2LN cells were grown in DMEM $4.5 \mathrm{~g} / \mathrm{L}$ glucose supplemented with $10 \%$ fetal calf serum (FCS), $1 \%$ nonessential amino acids, and $1 \%$ penicillin streptavidin and were maintained at $37^{\circ} \mathrm{C}$ in a $5 \% \mathrm{CO}_{2}$ atmosphere.

2.2. Lentiviral Vector Construct. The TRIPAU3-EF1 $\alpha$-FlaghAT2-IRES-GFP lentiviral vector (Figure 1) was constructed from a modified TRIP lentiviral vector $[30,31]$ by inserting the entire coding sequence of Flag-tagged human AT2 receptor (Flag-hAT2) between BamHI and XhoI restrictions sites upstream of the internal ribosomal entry site (IRES) GFP cassette. The human Flag-hAT2 sequence was amplified by PCR using the plasmid pBC-SF containing Flag-hAT2 cDNA (a generous gift of Dr. Laurent Daviet), the forward primer 5'-GCCGGATCCATGAAGACGATCATCGCCCTGAGC-3' containing the Flag initiating codon, and the reverse primer 5' -CGCTCGAGTTAAGACACAAAGGTCTCCATTTC-3' containing the stop codon of human AT2.
2.3. Lentiviral Production and Transduction. Production of infectious recombinant lentiviruses was performed by transient transfection of $293 \mathrm{~T}$ cells as described in [31]. For infections, $3 \times 10^{5}$ D3H2LN cells in $35 \mathrm{~mm}$ dishes were transduced with $5 \mu \mathrm{g} / \mathrm{mL}$ of viral p24 (HIV-1 capsid protein). $48 \mathrm{~h}$ later, cells were washed, and fresh medium was added. The resulting stable cell line D3H2LN-AT2 was grown in complete medium as described above for parental D3H2LN.

2.4. FACS Analysis. For FACS analysis, cells were detached with PBS-EDTA $1 \mathrm{mM}$, and $10^{6}$ cells were fixed in paraformaldehyde $4 \%$ for $10 \mathrm{~min}$. After 3 washes in PBS, GFP-positive cells were analyzed on FC-500 FACSCalibur flow cytometer using Cytomics RXP software.

2.5. Immunoprecipitation and Western Blotting. Cells were lysed one hour in ice with RIPA buffer containing $50 \mathrm{mM}$ Tris pH7.5, $100 \mathrm{mM} \mathrm{NaCl}, 50 \mathrm{mM}$ Na Fluoride, 0.1\% SDS, $0.5 \% \mathrm{Na}$ deoxycholate, and $1 \%$ Triton X-100 and extemporaneously supplemented by protease inhibitors $(1 \mathrm{mM}$ PMSF, $1 \mu \mathrm{g} / \mathrm{mL}$ aprotinin, $5 \mu \mathrm{g} / \mathrm{mL}$ leupeptin, and $1 \mu \mathrm{g} / \mathrm{mL}$ pepstatin). The cell lysate was directly used for Western blotting or incubated with $2 \mu \mathrm{g}$ of anti-Flag-M2 antibody (Sigma) overnight with rotation at $4{ }^{\circ} \mathrm{C}$ for FlagAT2 immunoprecipitation. Protein G sepharose beads (50\% slurry, Roche) were then added for an additional hour at $4^{\circ} \mathrm{C}$. The immunocomplexes were washed three times with lysis buffer and eluted in Laemmli's sample buffer containing urea $6 \mathrm{M}$.

After one hour denaturation at $60^{\circ} \mathrm{C}$, proteins and immunocomplexes were resolved on 10\% SDS-PAGE and transferred to PVDF membranes. Flag-hAT2 expression was revealed using Flag-M2-HRP antibodies and enhanced chemiluminescence (ECL+, GE Healthcare).

2.6. Competition Binding Assays. D3H2LN-AT2 cells $(3 \times$ $10^{5}$ cells/well) were transferred to 12 -well culture plates $24 \mathrm{~h}$ before binding assays. One day after plating, cells were washed briefly in $25 \mathrm{mM}$ Tris- $\mathrm{HCl}$ buffer, $\mathrm{pH} 7.4$ containing $140 \mathrm{mM} \mathrm{NaCl}, 5 \mathrm{mM} \mathrm{MgCl}_{2}$, and $0.1 \%$ BSA. Binding experiments were performed at $4^{\circ} \mathrm{C}$ to avoid any functional interference such as receptor activation, phosphorylation, or internalization. Binding was initiated by the addition of ${ }^{3} \mathrm{H}$ AngII (4pM) and increasing concentrations of nonradioactive AngII $\left(10^{-11} \mathrm{M}\right.$ to $\left.10^{-6} \mathrm{M}\right)$ as competitor, in a $500 \mu \mathrm{L}$ volume of binding buffer comprising $25 \mathrm{mM}$ Tris- $\mathrm{HCl}, \mathrm{pH}$ 7.4, $5 \mathrm{mM} \mathrm{MgCl}_{2}, 0.1 \% \mathrm{BSA}$, and $100 \mathrm{mg} / \mathrm{mL}$ bacitracin. Selective AT1 or AT2 receptor antagonists, losartan (Galena), and PD123319 (Sigma), respectively, were used at $10^{-6} \mathrm{M}$.

\section{Results and Discussion}

The aim of this study was to generate a useful cellular model for studying the role of AT2 receptors in breast cancer. To this end, we constructed and characterized a human breast cancer cell line stably expressing high amounts of human AT2 receptors at the plasma membrane. As a recipient for AT2 receptor expression, we chose the highly aggressive D3H2LN 


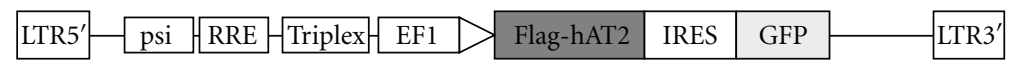

FIGURE 1: Schematic representation of the functional elements of the TRIP $\Delta$ U3-EF1 $\alpha$-Flag-hAT2-IRES-GFP lentiviral vector.

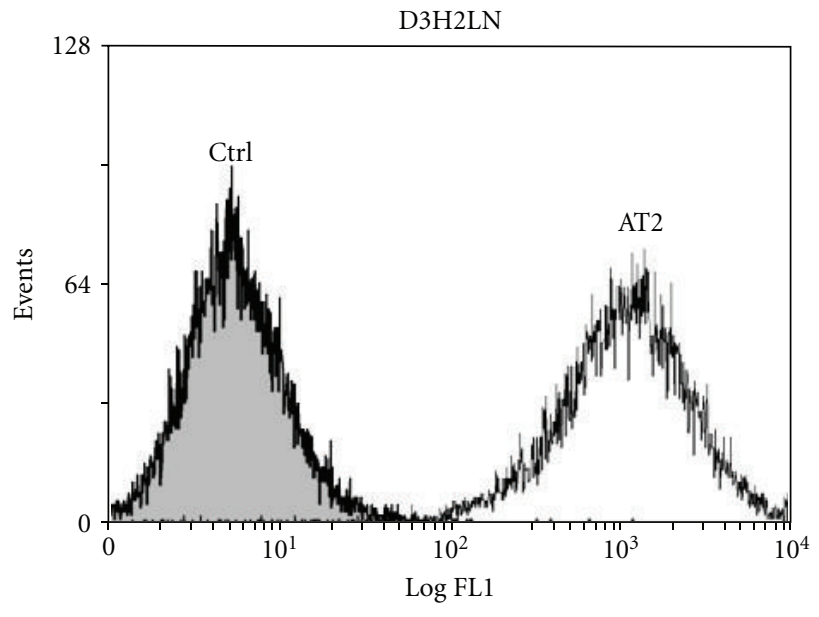

(a)

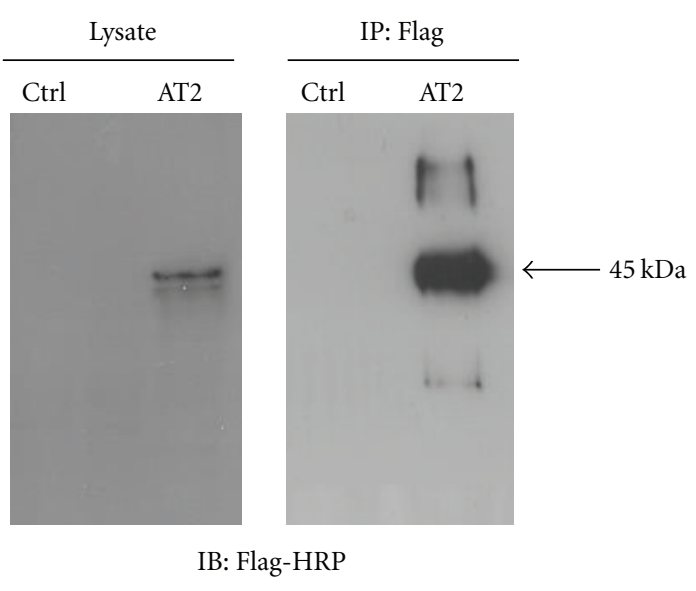

(b)

FIGURE 2: Validation of lentiviral vector transduction and expression in D3H2LN cell lines. (a) Flow cytometer analysis of GFP-positive cells. Grey-filled area represents noninfected parental D3H2LN cells (Ctrl), and white area represents infected D3H2LN-AT2 (AT2) cells. (b) Biochemical validation of Flag-AT2 expression by Western blotting (anti-Flag-HRP) in total cell lysate (left panel) or in anti-Flag immunoprecipitate fraction (right panel).

subline derived from the well-known metastatic and triplenegative breast cancer cells MDA-MB-231 [29]. D3H2LN cells are of particular interest for the study of breast cancer cell progression both in vitro and in vivo since they are highly invasive and metastatic. After intracardiac injection into nude mice, these cells rapidly disseminate and colonize distant organs including the brain, the lungs, and the bones [29] which are the major sites of metastasis in human breast cancer. In addition, D3H2LN cells constitutively express high levels of firefly luciferase, which will be most convenient for future in vivo bioluminescence analysis of tumor progression and metastatic dissemination in response to AT2 receptor activation.

Preliminary experiments indicated that D3H2LN cells express very low levels of endogenous AT2 receptor transcripts as assessed by RT-PCR (data not shown) which was a prerequisite for our study. We thus designed a human AT2 receptor-containing expression vector with the objective to reach high levels of expression of the AT2 receptor and easy detection of the receptor at the cell membrane. First, to facilitate AT2 receptor detection, we used a Flag-tagged human AT2 receptor (Flag-hAT2), which can be revealed by immunofluorescence and immunoprecipitation using antiFlag antibodies. We reasoned that by tagging the receptor at the extracellular $\mathrm{N}$-terminus, we would also be able to easily detect its expression at the plasma membrane. To fulfill the other criteria and maximize the expression efficiency, the Flag-hAT2 receptor sequence was cloned into a modified TRIP lentiviral vector containing IRES-GFP (Figure 1). This lentiviral vector is of great interest since it allows high levels of AT2 receptor expression, together with concomitant expression of the green fluorescent protein (GFP) that will serve as a positive control for infection efficiency. GFP expression will also be a valuable tool for the sensitive detection of the infected cells by FACS and immunofluorescence studies.

Lentiviral particles containing Flag-hAT2 were thus produced and used to transduce D3H2LN cells for $48 \mathrm{~h}$. Stably infected cells maintained in culture were thereafter designated "D3H2LN-AT2" cells and further characterized. Transduction efficiency was evaluated by flow cytometry measuring GFP-positive cells. As shown in Figure 2(a), $99.5 \%$ of the cells transduced with the AT2 lentiviral vector were positive for GFP expression, indicating that virtually all infected cells had incorporated the construct. We then evaluated whether D3H2LN cells also expressed detectable amounts of the AT2 receptor. To this end, we performed Western blotting and immunoprecipitation analyses using anti-Flag antibodies. As shown in Figure 2(b) (left panel), anti-Flag-HRP antibodies revealed a major polypeptide at $45 \mathrm{KDa}$ corresponding to the molecular weight of unglycosylated Flag-hAT2 receptor [32], in D3H2LN-AT2 but not in parental D3H2LN cells. Additional polypeptides of higher molecular weights ( 80 and $110 \mathrm{KDa})$ immunoprecipitated from D3H2LN-AT2 cells (Figure 2(b), right panel) might illustrate receptor dimerization or the presence of different glycosylated forms of the AT2 receptor [33].

In conclusion, in the present study, we successfully isolated a stable cell line (D3H2LN-AT2) constitutively expressing the Flag-tagged human AT2 receptor and concomitantly the GFP. To note, these cells remained stable in culture after more than 15 passages (data not shown). 


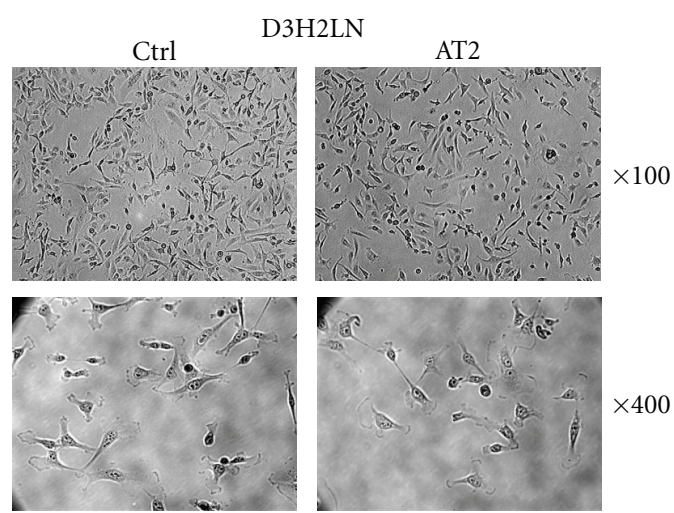

Figure 3: Morphological aspect of parental D3H2LN cells (Ctrl) or D3H2LN-AT2 cells (AT2). Pictures were taken under the microscope at $\times 100$ (upper panel) and $\times 400$ (lower panel) magnification.

To further characterize the D3H2LN-AT2 cells, culture dishes were placed under a phase contrast microscope, and pictures were taken at low $(\times 100)$ and high $(\times 400)$ magnification. As shown in Figure 3, there was no clear morphological differences between parental and D3H2LNAT2 cells, indicating that overexpression of AT2 receptors in D3H2LN breast cancer cells does not significantly alter cell structure, shape, or organization.

We next evaluated whether the ectopically expressed Flag-hAT2 receptor was localized at the cell surface of D3H2LN-AT2 and able to bind AngII with high affinity. To address these questions, competition binding experiments were performed on intact cells with tritium labeled AngII $\left({ }^{3} \mathrm{H}\right.$-AngII $)$ in the presence of increasing concentrations of unlabelled AngII. Results revealed a classical competition binding profile in D3H2LN-AT2 cells (Figure 4(a)), indicating the presence of a single population of receptors with an $\mathrm{IC}_{50}$ of $1.55 \pm 0.45 \mathrm{nM}(n=3)$ for AngII, as expected for a bona fide AngII receptor. In contrast, no specific AngII binding could be detected by binding assay in parental D3H2LN cells (data not shown), indicating that parental D3H2LN cells do not express detectable levels of AT1 and AT2 receptors in our experimental conditions.

As shown in Figure 4(b), total binding of 4pM radiolabelled AngII to D3H2LN-AT2 cells could be displaced (75\%) by adding an excess $(1 \mu \mathrm{M})$ of the selective AT2 receptor antagonist PD123319 but not in the presence of an excess of the AT1 receptor antagonist losartan. These results indicate that AT2 is the major AngII binding site in D3H2LN-AT2 cells. They also suggest that overexpression of AT2 in breast cancer cells does not modulate levels of membrane AT1 receptors. Thus, ectopically expressed Flag-hAT2 receptors in D3H2LN breast cancer cells are correctly folded at the plasma membrane and are able to bind the natural agonist with the expected high affinity. Total receptor density at the cell surface was quantified to $65 \mathrm{pmol}$ of receptor per $10^{5}$ D3H2LN-AT2 cells, which corresponds to a high level of receptors.

In conclusion, we report here the generation and characterization of a novel model of human invasive breast

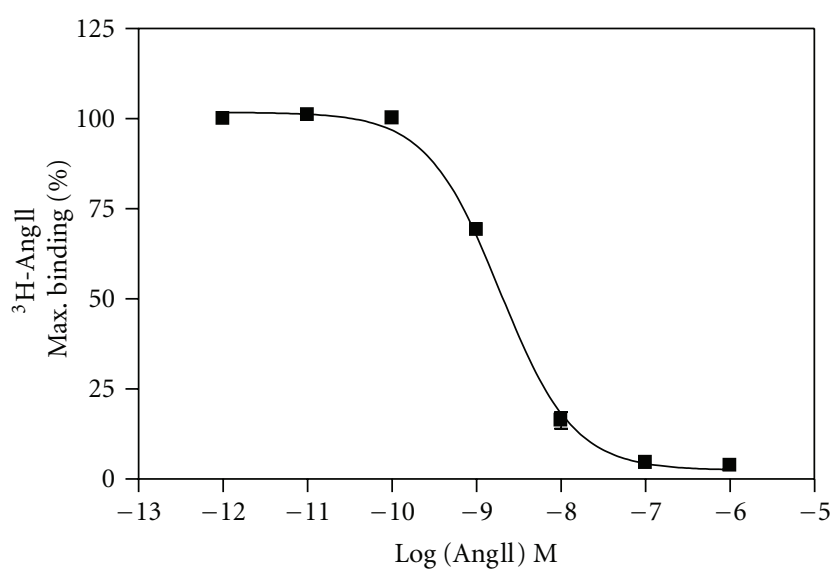

(a)

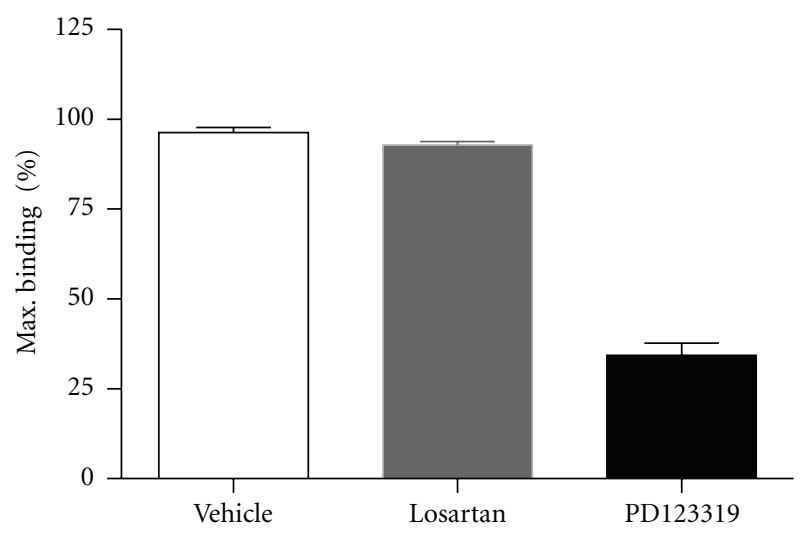

(b)

FIgUre 4: Binding studies. (a) Competition binding profile for AngII in D3H2LN-AT2 cells. Data are expressed as percentages of the maximum specific binding of the radioligand ${ }^{3} \mathrm{H}$-AngII. (b) Maximum binding obtained in the presence of the AT1 receptor antagonist (Losartan $10^{-6} \mathrm{M}$ ) or AT2 receptor antagonist (PD123319 $10^{-6} \mathrm{M}$ ), as compared to the control (vehicle). Values are means \pm SE of three independent experiments done in duplicate.

cancer cells (D3H2LN-AT2) that express high amounts of Flag-tagged human AT2 receptor at the plasma membrane. These cells also express GFP and luciferase, which makes them suitable for fluorescence and bioluminescence studies in vitro and in vivo. Of interest, D3H2LN-AT2 cells do not express detectable AT1 binding sites, as evaluated by radioligand binding assay, therefore allowing the characterization of AT2 functions independently of those related to AT1 receptor activation, which is of great interest in the context of AT1 blockade by ARBs.

Breast cancer is a leading cause of death by malignancy in women worldwide, and identifying new personalized therapeutic targets to fight this disease is a challenge for the coming years. Angiotensin receptors, being exposed at the plasma membrane, are easily targetable by selective receptor agonists or antagonists that may represent new and potent anticancer drugs. With the emergence of novel nonpeptidic 
selective agonists of the AT2 receptor such as compound $21[34,35]$, reliable tools are now available to evaluate the effects of this receptor in vitro and in vivo. There is urgent need to determine the effects of the AT2 receptor subtype in breast cancer. The cellular model presented here offers a unique opportunity to evaluate the consequences of AT2 receptor activation and blockade on breast cancer proliferation, invasion, and migration, as well as on tumor growth and metastasis formation.

\section{Conflict of Interests}

The authors declare that they have no conflict of interests.

\section{Acknowledgments}

The authors wish to thank the University Paris Descartes, the Institut National de la Santé et de la Recherche Médicale (Inserm), the Centre National pour la Recherche Scientifique (CNRS), the Ligue Contre le Cancer-Comité Ile de France, the Association pour la Recherche contre le Cancer (ARC), the association Prolific, and the São Paulo State Research Foundation (FAPESP, Brazil) for funding. The authors thank Didier Bordereaux for the generation of lentiviral constructs. C. M. Costa-Neto is on a leave of absence from the University of São Paulo (Brazil) at the College de France, Paris. V. Baud is supported by Agence Nationale pour la Recherche, Association pour la recherche sur le Cancer, Belgian Inter University Attraction Pole, Inserm, and Universite Paris Descartes. S. Rodrigues-Ferreira is supported by Roche Laboratories. S. Rodrigues-Ferreira and M. Morel contributed equally to this work.

\section{References}

[1] L. Paulis and T. Unger, "Novel therapeutic targets for hypertension," Nature Reviews Cardiology, vol. 7, no. 8, pp. 431-441, 2010.

[2] M. Bader, "Tissue renin-angiotensin-aldosterone systems: targets for pharmacological therapy," Annual Review of Pharmacology and Toxicology, vol. 50, pp. 439-465, 2010.

[3] F. Deshayes and C. Nahmias, "Angiotensin receptors: a new role in cancer?" Trends in Endocrinology and Metabolism, vol. 16, no. 7, pp. 293-299, 2005.

[4] C. Bouquet, N. Lamandé, M. Brand et al., "Suppression of angiogenesis, tumor growth, and metastasis by adenovirusmediated gene transfer of human angiotensinogen," Molecular Therapy, vol. 14, no. 2, pp. 175-182, 2006.

[5] F. Vincent, P. Bonnin, M. Clemessy et al., "Angiotensinogen delays angiogenesis and tumor growth of hepatocarcinoma in transgenic mice," Cancer Research, vol. 69, no. 7, pp. 28532860, 2009.

[6] L. Chow, L. Rezmann, K. J. Catt et al., "Role of the reninangiotensin system in prostate cancer," Molecular and Cellular Endocrinology, vol. 302, no. 2, pp. 219-229, 2009.

[7] A. J. George, W. G. Thomas, and R. D. Hannan, "The reninangiotensin system and cancer: old dog, new tricks," Nature Reviews Cancer, vol. 10, no. 11, pp. 745-759, 2010.
[8] T. Dolley-Hitze, F. Jouan, B. Martin et al., "Angiotensin-2 receptors (AT1-R and AT2-R), new prognostic factors for renal clear-cell carcinoma," British Journal of Cancer, vol. 103, no. 11, pp. 1698-1705, 2010.

[9] S. Nouet and C. Nahmias, "Signal transduction from the angiotens-in II AT2 receptor," Trends in Endocrinology and Metabolism, vol. 11, no. 1, pp. 1-6, 2000.

[10] M. Mogi, M. Iwai, and M. Horiuchi, "New insights into the regulation of angiotensin receptors," Current Opinion in Nephrology and Hypertension, vol. 18, no. 2, pp. 138-143, 2009.

[11] J. Stegbauer and T. M. Coffman, "New insights into angiotensin receptor actions: from blood pressure to aging," Current Opinion in Nephrology and Hypertension, vol. 20, no. 1, pp. 84-88, 2011.

[12] E. Rivera, O. Arrieta, P. Guevara, A. Duarte-Rojo, and J. Sotelo, "AT1 receptor is present in glioma cells; its blockage reduces the growth of rat glioma," British Journal of Cancer, vol. 85, no. 9, pp. 1396-1399, 2001.

[13] M. Fujita, I. Hayashi, S. Yamashina, M. Itoman, and M. Majima, "Blockade of angiotensin ATla receptor signaling reduces tumor growth, angiogenesis, and metastasis," Biochemical and Biophysical Research Communications, vol. 294, no. 2, pp. 441-447, 2002.

[14] A. Miyajima, T. Kosaka, T. Asano et al., "Angiotensin II type I antagonist prevents pulmonary metastasis of murine renal cancer by inhibiting tumor angiogenesis," Cancer Research, vol. 62, no. 15, pp. 4176-4179, 2002.

[15] H. Uemura, H. Ishiguro, and Y. Kubota, "Angiotensin II receptor blocker: possibility of antitumor agent for prostate cancer," Mini-Reviews in Medicinal Chemistry, vol. 6, no. 7, pp. 835844, 2006.

[16] M. Kosugi, A. Miyajima, E. Kikuchi, T. Kosaka, Y. Horiguchi, and M. Murai, "Effect of angiotensin II type 1 receptor antagonist on tumor growth and angiogenesis in a xenograft model of human bladder cancer," Human Cell, vol. 20, no. 1, pp. 1-9, 2007.

[17] K. Egami, T. Murohara, T. Shimada et al., "Role of host angiotensin II type 1 receptor in tumor angiogenesis and growth," Journal of Clinical Investigation, vol. 112, no. 1, pp. 67-75, 2003.

[18] N. Imai, T. Hashimoto, M. Kihara et al., "Roles for host and tumor angiotensin II type 1 receptor in tumor growth and tumor-associated angiogenesis," Laboratory Investigation, vol. 87, no. 2, pp. 189-198, 2007.

[19] D. R. Rhodes, B. Ateeq, Q. Cao et al., "AGTR1 overexpression defines a subset of breast cancer and confers sensitivity to losartan, an AGTR1 antagonist," Proceedings of the National Academy of Sciences of the United States of America, vol. 106, no. 25, pp. 10284-10289, 2009.

[20] I. Sipahi, S. M. Debanne, D. Y. Rowland, D. I. Simon, and J. C. Fang, "Angiotensin-receptor blockade and risk of cancer: meta-analysis of randomised controlled trials," The Lancet Oncology, vol. 11, no. 7, pp. 627-636, 2010.

[21] S. Connolly, S. Yusuf, K. Swedberg et al., "Effects of telmisartan, irbesartan, valsartan, candesartan, and losartan on cancers in 15 trials enrolling 138769 individuals," Journal of Hypertension, vol. 29, no. 4, pp. 623-635, 2011.

[22] S. Bangalore, S. Kumar, S. E. Kjeldsen et al., "Antihypertensive drugs and risk of cancer: network meta-analyses and trial sequential analyses of 324168 participants from randomised trials," The Lancet Oncology, vol. 12, no. 1, pp. 65-82, 2011. 
[23] C. Doi, N. Egashira, A. Kawabata et al., "Angiotensin II type 2 receptor signaling significantly attenuates growth of murine pancreatic carcinoma grafts in syngeneic mice," BMC Cancer, vol. 10, article 67, 2010.

[24] L. Pickel, T. Matsuzuka, C. Doi et al., "Overexpression of angiotensin II type 2 receptor gene induces cell death in lung adenocarcinoma cells," Cancer Biology and Therapy, vol. 9, no. 4, pp. 277-285, 2010.

[25] M. J. Brown, I. S. Mackenzie, M. J. Ashby, K. K. Balan, and D. S. Appleton, "AT2 receptor stimulation may halt progression of pheochromocytoma," Annals of the New York Academy of Sciences, vol. 1073, pp. 436-443, 2006.

[26] O. Arrieta, B. Pineda-Olvera, P. Guevara-Salazar et al., "Expression of AT1 and AT2 angiotensin receptors in astrocytomas is associated with poor prognosis," British Journal of Cancer, vol. 99, no. 1, pp. 160-166, 2008.

[27] N. Clere, I. Corre, S. Faure et al., "Deficiency or blockade of angiotensin II type 2 receptor delays tumorigenesis by inhibiting malignant cell proliferation and angiogenesis," International Journal of Cancer, vol. 127, no. 10, pp. 22792291, 2010.

[28] B. De Paepe, V. L. Verstraeten, C. R. De Potter, and G. R. Bullock, "Increased angiotensin II type-2 receptor density in hyperplasia, DCIS and invasive carcinoma of the breast is paralleled with increased iNOS expression," Histochemistry and Cell Biology, vol. 117, no. 1, pp. 13-19, 2002.

[29] D. E. Jenkins, Y. S. Hornig, Y. Oei, J. Dusich, and T. Purchio, "Bioluminescent human breast cancer cell lines that permit rapid and sensitive in vivo detection of mammary tumors and multiple metastases in immune deficient mice," Breast Cancer Research, vol. 7, no. 4, pp. R444-454, 2005.

[30] A. Sirven, E. Ravet, P. Charneau et al., "Enhanced transgene expression in cord blood $\mathrm{CD} 34^{+}$-derived hematopoietic cells, including developing $\mathrm{T}$ cells and NOD/SCID mouse repopulating cells, following transduction with modified TRIP lentiviral vectors," Molecular Therapy, vol. 3, no. 4, pp. 438448, 2001.

[31] A. Kieusseian, J. Chagraoui, C. Kerdudo et al., "Expression of Pitx2 in stromal cells is required for normal hematopoiesis," Blood, vol. 107, no. 2, pp. 492-500, 2006.

[32] D. Lazard, M. M. Briend-Sutren, P. Villageois, M. G. Mattei, A. D. Strosberg, and C. Nahmias, "Molecular characterization and chromosome localization of a human angiotensin II AT2 receptor gene highly expressed in fetal tissues," Receptors and Channels, vol. 2, no. 4, pp. 271-280, 1994.

[33] D. Lazard, P. Villageois, M. M. Briend-Sutren et al., "Characterization of a membrane glycoprotein having pharmacological and biochemical properties of an AT2 angiotensin II receptor from human myometrium," European Journal of Biochemistry, vol. 220, no. 3, pp. 919-926, 1994.

[34] X. Wu, Y. Wan, A. K. Mahalingam et al., "Selective angiotensin II AT2 receptor agonists: arylbenzylimidazole structureactivity relationships," Journal of Medicinal Chemistry, vol. 49, no. 24, pp. 7160-7168, 2006.

[35] U. M. Steckelings, M. Larhed, A. Hallberg et al., "Non-peptide AT2-receptor agonists," Current Opinion in Pharmacology, vol. 11, no. 2, pp. 187-192, 2011. 

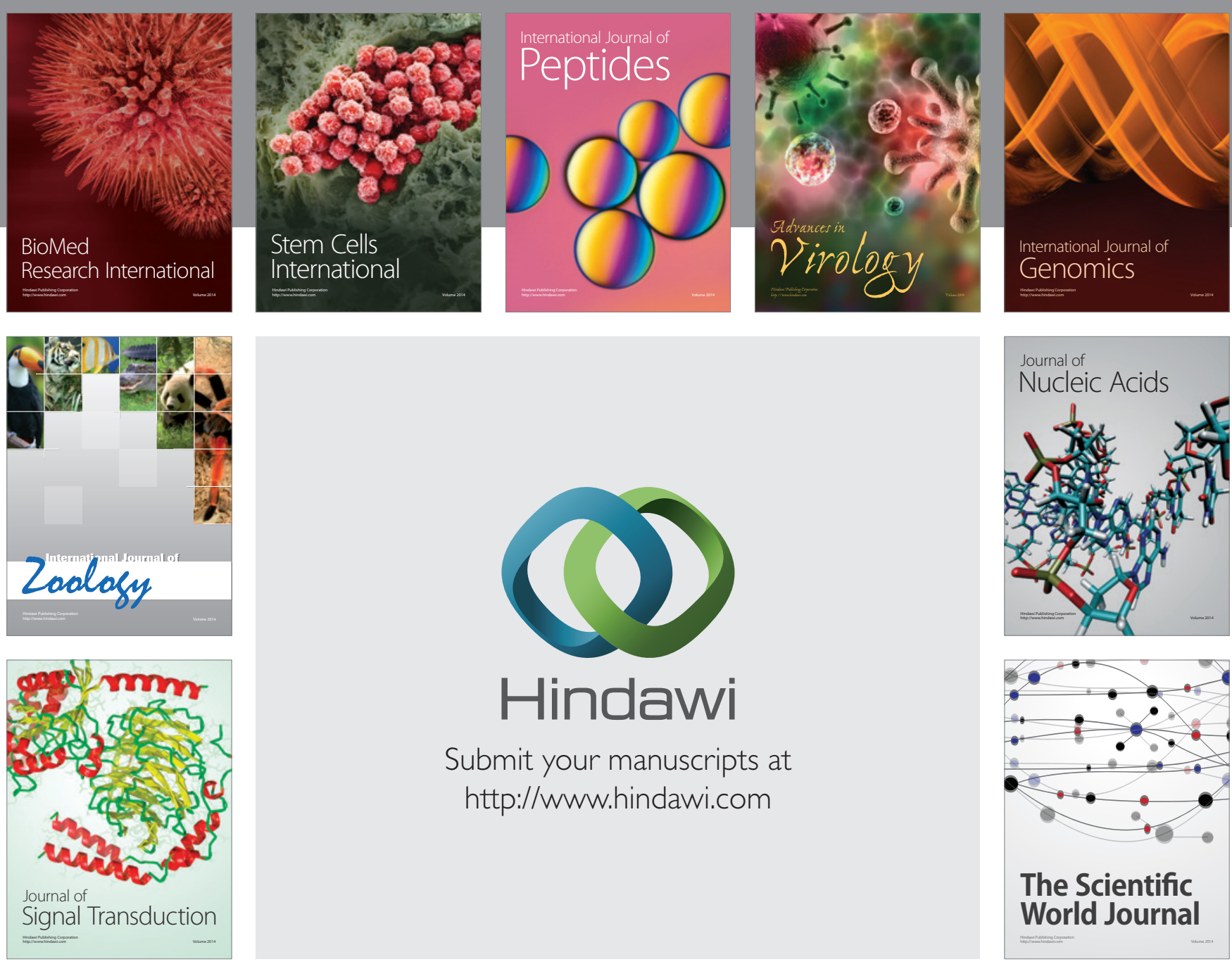

Submit your manuscripts at

http://www.hindawi.com
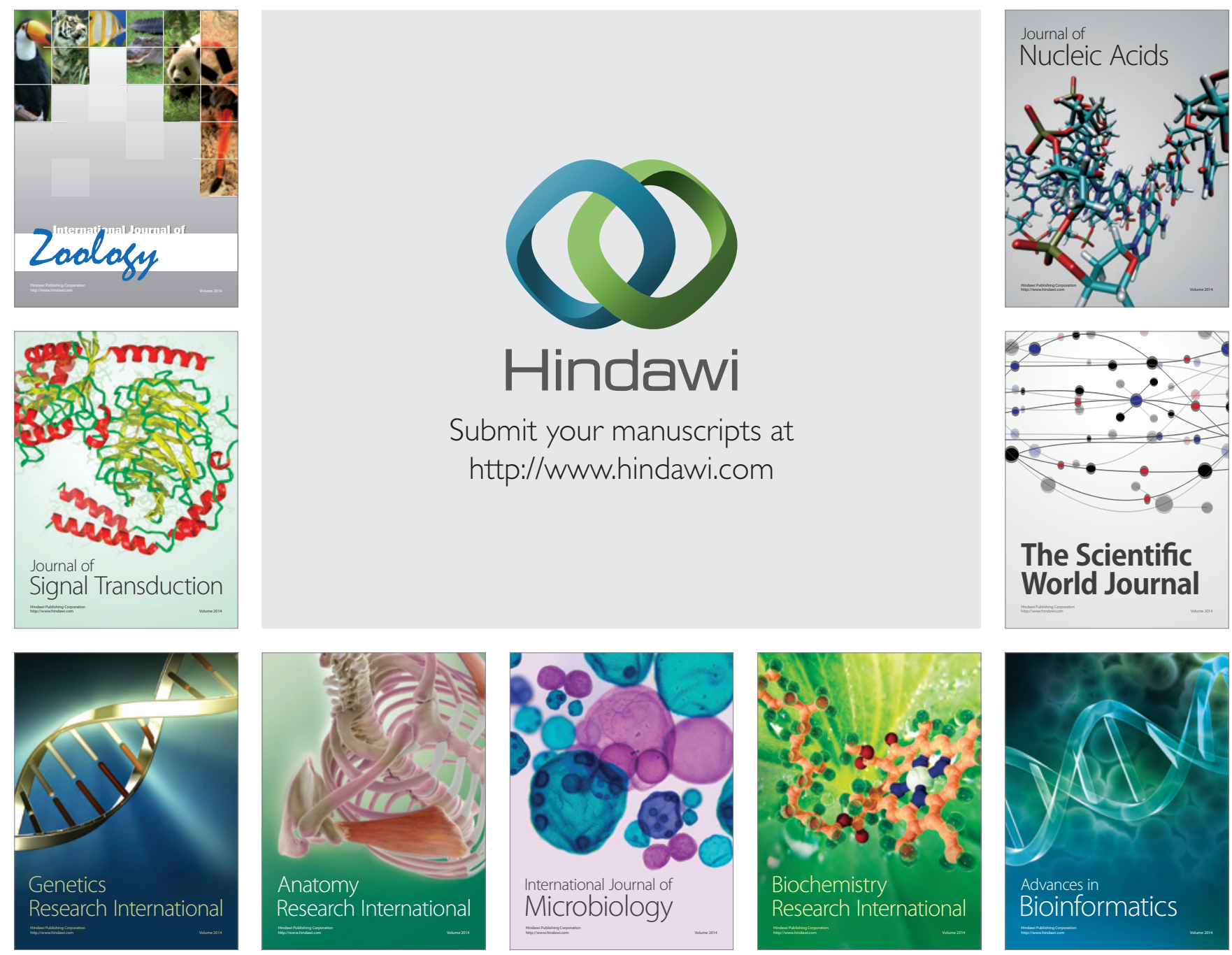

The Scientific World Journal
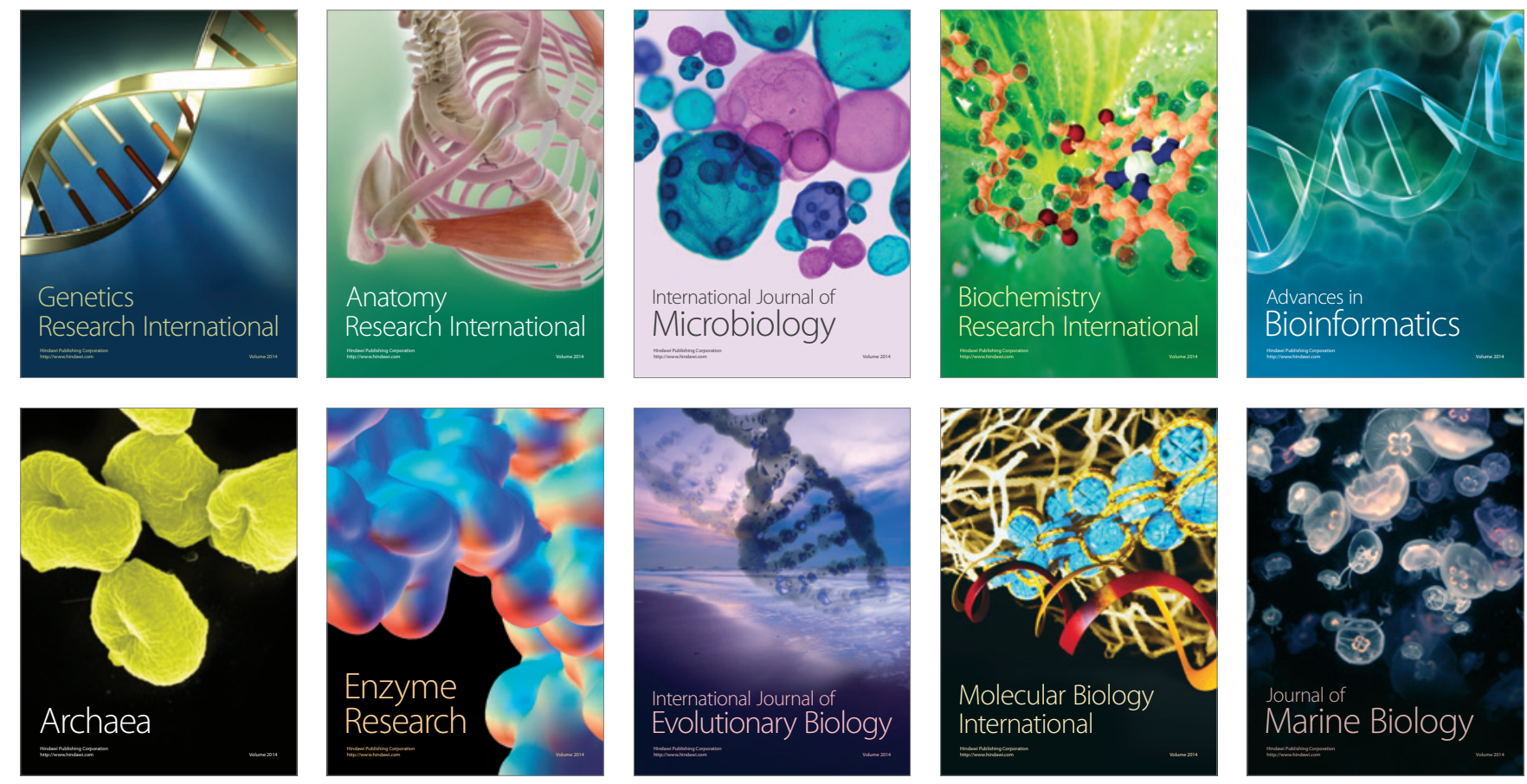